\title{
Döviz Kuru Oynaklığı ve Ekonomik Büyüme: Türkiye Örneği
}

\author{
Hidayet $\ddot{U} N \mathbf{U}$, Department of Economics, Faculty of Economics and Administrative Sciences, Suleyman \\ Demirel University, Turkey; e-mail: hidayetunlu@sdu.edu.tr
}

\section{Exchange Rate Volatility and Economic Growth: The Case of Turkey}

\begin{abstract}
The relation between the real exchange rate volatility and economic growth is among the remarkable study topics. How does this exchange rate volatility shape the investment and economic growth? In literature, there exist many studies that seek an answer to this question. In this study, an answer is searched for this mentioned question by investigating the impacts of real exchange rates over the output growth in Turkey. In this study, the impacts of consumer price index (CPI), gross fixed capital formation (GFCF), foreign direct investment (FDI) and real exchange rate volatility (RERV) on real gross domestic product (RGDP) of Turkey, are investigated using data of quarterly periods from 1998:Q1 to 2014:Q3. In reference to ARDL bounds test approach, it is concluded that there has been a long term relation among the variables. While consumer price index (CPI) and gross fixed capital formation (GFCF) variables have a positive and statistically significant impact on (RGDP), the coefficient of foreign direct investment (FDI) variables is also positive but not significant. Real exchange rate volatility (RERV) variable has a negative and statistically significant impact on real gross domestic product (RGDP). This result shows that the real exchange rate volatility in Turkey have negative impacts on the output.
\end{abstract}

Keywords

Real Exchange Rate Volatility, Economic Growth, ARDL Bounds Test.

JEL Classification Codes : $\quad$ E31, F31, O40.

Öz

Döviz kuru oynaklığı ve ekonomik büyüme arasındaki ilişki ilgi uyandıran araştırma konularındandır. Döviz kuru oynaklığı, yatırımı ve bununla bağlantılı olarak ekonomik büyümeyi nası1 şekillendirmektedir? Literatürde bu soruya cevap arayan çok sayıda çalışma mevcuttur. Çalışmada bu soruya reel döviz kuru oynaklığının Türkiye'de çıktı üzerindeki etkileri üzerinden cevap aranmaya çalışılmıştır. Bu çalışmada Türkiye'nin reel gayri safi yurt içi hasılası (RG) üzerinde tüketici fiyat endeksi(TÜFE), gayri safi sabit sermaye oluşumu (SSO), doğrudan yabancı sermaye yatırımı (DYSY) ve döviz kuru oynaklığ (OYN) etkileri 1998:Ç1 den 2014:Ç3'e kadar üçer aylık veriler kullanılarak incelenmiştir. ARDL Sınır Testi yaklaşımına göre değişkenler arasında uzun dönemli bir ilişkinin var olduğu sonucuna ulaşılmıştır. TÜFE ve SSO değişkenleri RG üzerinde pozitif ve anlamlı bir etkiye sahipken, DYSY değişkeninin katsayısı da pozitiftir fakat anlamlı değildir. OYN değişkeni RG üzerinde negatif ve anlamlı bir etkiye sahiptir. Bu sonuç, Türkiye'de reel döviz kurunda yaşanan dalgalanmaların çıtı üzerinde olumsuz etkilere sahip olduğunu göstermektedir. 
Ünlü, H. (2016), “Döviz Kuru Oynaklığı ve Ekonomik Büyüme:

Türkiye Örneği”, Sosyoekonomi, Vol. 24(27), 11-24.

\section{Giriş}

Döviz kuru ve ekonomik büyüme arasındaki ilişki hakkında genelde iktisatçılar arasında tartışmalı görüşler bulunmaktadır ya da başka bir ifadeyle tam bir görüş birliği yoktur. Döviz kuru genel olarak bir birim ulusal parayla ne kadar yabancı para birimi alınabildiğini gösteren değişim oranı olarak tanımlanmaktadır (Ahmad, 2013: 741). Başka bir tanıma göre döviz kuru, bir para biriminin ilişkide bulunduğu başka bir para birimine karşı fiyatıdır. Bu tanıma göre döviz kuru, dönüştürme işleminin yönüne bağlı olan bir dönüştürme aracı, bir katsayı veya oran olarak ifade edilmektedir (Azid vd., 2005: 749-750). Reel döviz kuru, fiyat değişimlerinden arındırılmış nominal döviz kurudur ve bir ülkenin rekabetçiliğini gösteren önemli bir makro ekonomik politika değişkeni olarak görülmektedir (Kogid vd., 2012: 7). Birçok çalışmada belirtildiği üzere döviz kuru, ekonomik büyümeyi iki kanalla pozitif etkileyebilmektedir. Birincisi döviz kuru nakit riskini azaltmakta ve bu sayede faiz oranlarını düşürmektedir. $\mathrm{Bu}$ durum da yatırımı ve büyümeyi artırmaktadır. İkincisi döviz kuru uluslararası ticaretle bağlantılı olarak uluslararası işlem maliyetlerini düşürerek büyümeyi etkileyebilmektedir (Dornbush, 2001: 5). Literatürde döviz kuru oynaklığı yatırımı ve bununla bağlantılı olarak ekonomik büyümeyi nasıl etkilemektedir sorusunu araştıran çok sayıda çalışma bulunmaktadır.

Öncelikle döviz kuru oynaklığının tanımı yapmak faydalı olacaktır. Oynaklık, kısa süre içinde değişkenlerin değerlerinin belirli bir ortalamadan uzaklaşması anlamına gelmektedir (Akay \& Nargeleçekenler, 2006: 5). Oynaklık; istikrarsızlık, belirsizlik veya kararsızlık olarak tanımlanmakta ve riskin bir ölçüsü olarak görülmektedir. Aynı zamanda oynaklık, varlık fiyatlamada, portföy optimizasyonunda, opsiyon fiyatlamasında ve risk yönetimindeki riskin bir ölçüsü olarak değerlendirilmektedir. Dolayısıyla oynaklık çeşitli ekonomi kararlarında girdi olarak kullanılabilecek bir risk ölçüm değişkeni sunmaktadır. Döviz kuru oynaklığı ise hem mal piyasası hem de finansal varlıklar piyasasındaki uluslararası işlemlerde belirsizlik olarak tanımlanmaktadır. Buna ek olarak döviz kuru oynaklığı ekonomideki birimlerin para arzında, faiz oranlarında ve gelirde yaşanan değişimler hakkında beklentilerini yansıtmaktadır. Makroekonomik teoride iki alan döviz kuru oynaklığının makroekonomik performansı nasıl etkilediği sorusu ile ilgilenmektedir. Bunlardan birincisi ulusal ekonominin farklı döviz kuru rejimleri altında yabancı ve ulusal, reel ve parasal şoklara nasıl tepki verdiğini araştırmaktadır. İkincisi ise esnek döviz kuru rejimlerinde döviz kuru oynaklığının uluslararası ticareti nasıl etkilediği konusuna odaklanmaktadır (Azid vd., 2005: 749-750).

Ekonomik teoriye göre döviz kuru, parasal bir araç gibi hareket ederek uzun dönem büyümeyi özellikle negatif etkileyebilmektedir (Miles, 2006: 92). Genel olarak döviz kuru oynaklığının dış ticaret, turizm, uluslararası finansal akımlar, yatırım ve üretim üzerinde olumsuz etkileri bulunduğu kabul edilmektedir (Güloğlu \& Akman, 2007: 44). Ayrıca döviz kuru oynaklığının ekonomik büyüme için önemli olan ticareti ve yatırımı azalttığı belirtilmektedir (Eichengreen, 2007: 3). Reel döviz kuru oynaklığı yatırım kararları 
için belirsiz bir çevre oluşturmakta ve böyle bir ortamda yatırımcılar kur hakkında daha fazla bilgi sahibi olabilmek için yatırım kararlarını ertelemektedir. Bu durumda da ekonomik performans üzerinde büyük bir negatif güç oluşturmaktadır. Aynı zamanda reel döviz kuru belirsizliği kaynakların sektörler ve ülkeler arasında yeniden dağıtılmasına neden olarak yatırım için yine belirsiz bir ortam sunmaktadır (Azid vd., 2005: 749-750). Buna ek olarak ekonomide risk yaratarak büyüme ve kalkınmayı olumsuz etkileyebilmektedir (Kogid vd., 2012: 9). Bu çalışmada reel döviz kuru oynaklığı ve ekonomik büyüme arasındaki ilişki incelenmiştir. Çalışmada bağımlı değişken olarak ekonomik büyümeyi temsilen reel GSYİH (RG) alınmıştır. Modelin bağımsız değişkenleri ise reel döviz kuru oynaklığı (OYN), enflasyon (TÜFE), doğrudan yabancı sermaye yatırımı (DYSY) ve gayri safi sabit sermaye oluşumu (SSO)'dur.

\section{Literatür Taraması}

Literatürün büyük bir kısmı döviz kuru oynaklığının reel faaliyetler üzerindeki etkisinin çok küçük veya anlamsız olduğunu iddia etmektedir. Aghion vd. ise çalışmalarında reel döviz kuru oynaklığının verimlilik artışı üzerinde anlamlı bir etkisi olduğuna dair ampirik kanıtlar sunmuş ayrıca ulusal kredi piyasaları açısından reel döviz kuru belirsizliklerinin negatif yatırım etkisi için basit bir parasal büyüme modeli oluşturmuştur (2009: 494). Buna ek olarak, Campa ve Goldberg, döviz kuru oynaklığının yatırımlar üzerinde negatif etkisi olduğunu fakat bu kantitatif etkinin çok küçük olduğunu belirtmiştir (1993: 2). Aizenman, döviz kuru oynaklığı ve yatırım arasında pozitif bir ilişki bulmuştur (1992). Campa ve Goldberg başka bir çalışmalarında ise döviz kuru oynaklığının yatırım üzerinde hiçbir etkisi olmadığını belirtmiştir (1995: 318).

Ekonomik büyüme ve kalkınma üzerine Ahmad vd.'nin 2012 yılında yaptı̆̆ çalışmada Pakistan'ın GSYİH ve toplam yatırım arasındaki ilişkisi 1971-2011 periyodu için zaman serileri analizi kullanılarak incelenmiş, yatırım ve ekonomik büyüme arasında pozitif ve anlamlı bir ilişki bulunmuştur. Çalışmada yatırımdaki \%1'lik artışın GSYİH'y1 \%0.89 artırdığını belirtmiştir (2012b: 680). Ahmad vd. 2013'teki çalışmalarında ise Pakistan'ın ekonomik büyümesi üzerinde enflasyon ve döviz kuru oranı arasında negatif ve anlamlı bir etki bulunduğunu belirtmişlerdir. Enflasyondaki \%1'lik artış, GSYİH'yı \%0.29 düşürmektedir. Döviz kuru oranında \%1'lik artış, GSYİH'yı \%0.55 azaltmaktadır. Sermeye stoğunun ekonomik büyümeyi anlamlı ölçüde etkilemediğini belirtmiştir. DYSY ise Pakistan'ın ekonomik büyümesi üzerinde pozitif ve anlamlı etkisi bulunmaktadır. DYSY'daki \%1'lik artış GSYİH’yı \%0.37 artırmaktadır (2013: 740).

Javed ve Farooq, uzun dönemde döviz kuru oynaklığı ve ekonomik büyüme arasında pozitif ilişki olduğunu belirmiştir. ARDL modelini kullanarak 1982:1'den 2007:4'e kadar olan dönem için Pakistan'da döviz kuru oynaklığı ve ekonomik büyüme arasındaki ilişkiyi araştırmışlardır. Ayrıca ulusal ekonomik performansın uzun dönemde döviz kuru oynaklığına çok duyarlı olduğunu belirtmişlerdir (2009: 112). He, Çin'deki ekonomik büyüme ve döviz kuru arasındaki ilişkiyi incelemiştir. He'ye göre Çin sabit döviz kuru politikası uygulamış ve hızlı ekonomik büyümeyi sağlamıştır. Ayrıca sabit döviz kuru 
uygulamasının uzun dönemde verimlilik yarattığını da belirtmiştir (2010: 36). Tarawalie, Sierra Leone'nın ekonomik büyümesi üzerinde reel döviz kurunun etkisini araştırmıştır. 1996-2006 arası için çeyrek dönemlik verileri ve Granger nedensellik testini kullanmıştır. Araştırması sonucunda reel döviz kuru ve ekonomik büyüme arasında pozitif korelasyon bulmuştur (2010: 8). Cheung ve Lai, 5 Asya ülkesinde döviz kuru oranı ve ekonomik büyüme arasında pozitif ilişki olduğu sonucunu bulmuştur (1998: 61). Rodrik, gelişmiş ve gelişmekte olan ülkeler arasındaki asimetriyi 184 ülkenin 1960-2004 yılları arasındaki verilerini kullanarak araştırmış ve reel döviz kurunun değerinin altında değere sahip olmasının ekonomik büyüme üzerinde gelişmiş ülkelere oranla gelişmekte olan ülkelerde çok daha güçlü ve anlamlı bir etkisi olduğunu bulmuştur (2008: 365). Chen, 1992-2008 yılları arasındaki dönem için Çin'deki 28 eyaletin verilerini kullanarak döviz kuru ve ekonomik büyüme arasındaki ilişsiyi araştırmıştır. Çalışmasının sonucunda reel döviz kurunun değerlenmesinin Çin'deki eyaletlerin ekonomik büyümesi üzerinde pozitif etkisi olduğunu belirtmiştir (2012: 1). Musyoki vd. ise reel döviz kuru oynaklığının ekonomik büyüme üzerinde negatif etkisi olduğunu belirtmiştir (2012: 59). Vieira vd., 2013 yılındaki çalışmasında, reel döviz kuru oynaklığının uzun dönem ekonomik büyüme üzerindeki etkisini 82 tane gelişmiş ve gelişmekte olan ülkenin 1970-2009 dönemi verileri ile panel veri seti kullanılarak araştırılmıştır. Çalışma sonucunda oynaklığı daha yüksek bir reel döviz kuru oranının ekonomik büyüme üzerinde negatif ve anlamlı bir etkisi olduğu başka bir ifadeyle oynaklığı daha az bir reel döviz kuru oranının ekonomik büyüme üzerinde pozitif ve anlamlı bir etkisi olduğu bulunmuştur (2013: 3733).

Enflasyon ve ekonomik büyüme arasındaki ilişkiyi inceleyecek olursak yine her bir iktisatçının birbirinden farklı görüş sunduğu bir tartışma ortamı olduğu görülmektedir. Bazı iktisatçılar enflasyon ve büyüme arasında hiçbir ilişki olmadığını iddia etmektedir. Bazı iktisatçılar ise enflasyon ve ekonomik büyüme arasında pozitif ve anlamlı bir ilişki olduğunu belirtirken, enflasyon ve ekonomik büyüme arasında ters yönlü bir ilişki olduğunu iddia eden görüşler de bulunmaktadır (Ahmad vd., 2013: 742). Enflasyonla ilgili yapılan akademik çalışmalara baktığımızda Ahmad ve Joyia'nın, Pakistan'ın GSYİH'sı ile enflasyonu arasındaki ilişkiyi araştırdığı çalışmada, GSYİH ile enflasyon arasında pozitif bir ilişki olduğu bulunmuştur. Enflasyondaki \%1'lik artış GSYİH'yı \%0.45 artırmaktadır. Bu çalışmaya göre enflasyon, çıktı seviyesini ve verimliliği teşvik etmektedir. Fakat enflasyonun yönetilmesi gerekmektedir aksi takdirde zararlı sonuçlar oluşturabilmektedir (2012: 38), Ahmad ve Luqman, 2012 yılında 1971-2011 yılları arasındaki verileri kullanarak Pakistan'nın GSYİH'sını bağımlı değişken, enflasyon, ihracat, yatırım ve nüfus artış oranını ise bağımsız değişkenler olarak kullanarak bir araştırma gerçekleştirmiştir. Çalışma sonucunda Pakistan'ın ekonomik büyümesi ile enflasyon oranı arasında negatif ve anlamlı bir ilişki bulunmuştur (2012: 180). Shahzad ve Malik (2012: 262), Naseer vd. (2012: 4000) ve Mubarik (2005: 35); çalışmalarında ekonomik büyüme ve enflasyon arasında pozitif ilişki bulmuştur. Bruno ve Easterly (1998: 3), Huybens (1999: 283), Quartey (2010: 180), Ghosh ve Phillips (1998: 662) ve Barro (1995: 2), çalışmalarında enflasyon ve ekonomik büyüme arasında negatif ve anlamlı bir sonuç bulmuştur. Mughal vd. (2012: 6108) ise enflasyon ve ekonomik büyüme arasında hiçbir ilişki bulmamıştır. 
Doğrudan yabancı sermeye yatırımları (DYSY) ise ekonomik büyümeye etkisi merak edilen diğer bir değişkendir. Birçok araştırmacı DYSY'nın bir ülkenin ekonomik büyümesinin itici gücü gibi çalıştığına vurgu yapmaktadır. Bu görüşe göre yeterli düzeyde yabancı doğrudan yatırım olmadan sürdürülebilir büyüme sağlamak mümkün değildir. Ahmad vd. çalışmalarında, Pakistan'ın GSYİH'sını bağımlı değişken, DYSY, ulusal sermaye ve işgücünü ise bağımsız değişkenler olarak kullanmış ve Pakistan'da DYSY ve ekonomik büyüme arasında pozitif ve anlamlı bir ilişki olduğunu bulmuşlardır. Pakistan'ın kalkınması için DYSY çekmesi gerektiğini belirtmişlerdir (2012b: 21). Mahmood ve Major (2011: 388) ve Khaliq ve Noy (2007: 1) DYSY'nın ekonomik büyüme için önemli bir araç olduğunu belirtmektedir. Bunun yanında DYSY'nın ekonomik büyüme üzerinde önemli bir etkisinin olmadığını belirten çalışmalar da mevcuttur. Carkovic ve Levine, ekonomik büyüme ve DYSY arasındaki ilişkiyi araştırmış ve DYSY'nın ekonomik büyüme üzerinde önemli ve bağımsız bir etkisinin olmadığını bulmuştur (2002: 1). Carkovic ve Levine başka bir çalışmasında DYSY'nın ulusal sermayeyi dışlayıcı etki yarattığını ve bu nedenle ekonomik büyüme üzerindeki etkisinin anlamsız veya negatif olduğunu belirtmiştir (2005: 196, 219). Aitken ve Harrison'da 1999 yılındaki Venezuela ile ilgili çalışmalarında DYSY'nın pozitif yayılma sağladığına dair görüşleri reddetmiştir (1999: 605).

\section{Veri Seti ve Metodoloji}

Ekonometrik modelde bağımlı değişken olarak ekonomik büyümeyi temsil eden Reel GSYİH (RG) verileri TCMB EVDS'den alınmıştır. Bağımsız değişkenler TÜFE, DYSY, SSO ve Reel Döviz Kuru (RDK) verileri ise IMF Uluslararası Finansal İstatistikler (IFS) veri tabanından elde edilmiştir. RDK verileri aracılığıyla kurulan GARCH modeline ait koşullu varyans değerleri modelde oynaklık (OYN) değişkeni olarak kullanılmıştır. Bu çalışmada 1998:Ç1'den 2014:Ç3'e kadar olan üçer aylık veriler kullanılmıştır. Reel döviz kuru oynaklığı, özellikle ithal mallarının yurtiçi maliyetleri üzerindeki etkisi nedeniyle üretim üzerindeki öngörülemeyen riskleri yansıtmaktadır. Gözlenemeyen bir değişken olması nedeniyle reel döviz kuru oynaklığı, GARCH modelinden (Bollerslev, 1986) elde edeceğimiz koşullu varyans değerleri ile ölçülecektir.

$$
R D K=a+\phi_{i} \sum_{i=1}^{p} R D K_{t-i}+\varepsilon_{t} ; \quad \varepsilon \sim N\left(0, \sigma^{2}\right)
$$

Denklem 1'deki a sabit terimdir. Bu formüldeki $\phi_{i}$ katsayıları ve $\varepsilon_{t}$ ise ortalama sıfır ve varyans $\sigma^{2}$ iken normal dağılan hata terimini göstermektedir. $\sigma_{t}^{2}$, reel döviz kurunun koşullu varyansıdır. $\varepsilon_{t-1}^{2}$ ise denklem 2'de (ortalama denklem) hata terimlerinin karelerini göstermektedir. Bununla birlikte $\operatorname{GARCH}(\mathrm{p}, \mathrm{q})$ süreci ARCH'ın daha geniş bir fonksiyonudur. Bu fonksiyonda koşullu varyansın gecikmeli değerleri de modelde açıklayıcı değişken olarak yer almaktadır. Reel döviz kurunun koşullu varyansı şu şekildedir:

$$
\sigma_{t}^{2}=a+\sum_{i=1}^{p} \varepsilon_{t-i}^{2}+\sum_{j=1}^{q} \sigma_{t-j}^{2}+u_{t}
$$

Durağan olmayan zaman serilerini test ederken en yaygın karşılaşılan sorun, birim kök testlerinin çok düşük etkiye sahip olmasıdır. Bu nedenle özellikle son yıllarda, 
uzun dönemli ilişkilerin test edilmesinde Pesaran ve Shin (1999) ve Pesaran ve diğerleri (2001) tarafından geliştirilen ARDL sınır testi yaklaşımı kullanılmaktadır. Bu metodun en belirgin özelliği; değişkenler arasında uzun dönemli ilişkinin test edilmesi için her bir değişkenin bütünleşme derecesinin aynı olması koşuluna sahip olmamasıdır. Diğer bir ifadeyle, değişkenlerin I(0) veya I(1) olması uzun dönemli ilişkinin test edilmesinde bir ön koşul olmaktan çıkmaktadır. Buna ek olarak, uzun ve kısa dönem katsayıları eş zamanlı olarak tahmin edilebilir ve dinamik bir hata düzeltme modeli (ECM), ARDL modeli üzerinden basit bir doğrusal dönüşümle elde edilebilir. Bu yöntemin uygulanmasıyla ARDL modelinin hata düzeltme varsayımı şu şekilde olur:

$$
\begin{aligned}
\Delta R G_{t}=a+\varphi_{1} R G_{t-1} & +\varphi_{2} T U F E_{t-1}+\varphi_{3} D Y S Y_{t-1}+\varphi_{4} S S O_{t-1}+\varphi_{5} O Y N_{t-1}+\delta_{1} \sum_{i=1}^{k} \Delta R G_{t-i} \\
& +\delta_{2} \sum_{i=0}^{k} \Delta T U F E_{t-i}+\delta_{3} \sum_{i=0}^{k} \Delta D Y S Y_{t-i} \\
& +\delta_{4} \sum_{i=0}^{k} \Delta S S O_{t-i}+\delta_{5} \sum_{i=0}^{k} \Delta O Y N_{t-i}+u_{t}
\end{aligned}
$$

Denklem 3 'te a sabit terimi, $\varphi$ uzun dönem katsayıları, $\delta$ kısa dönem katsayıları ve $u$ hata terimini temsil etmektedir. Uzun dönemli ilişkiyi test etmek için, F istatistiği yardımıyla uzun dönemde eş bütünleşme olmadığını söyleyen $H_{0}: \varphi_{1}=\varphi_{2}=\varphi_{3}=\varphi_{4}=\varphi_{5}=0$ yokluk hipotezine karşılık, $H_{0}: \varphi_{1} \neq \varphi_{2} \neq \varphi_{3} \neq \varphi_{4} \neq \varphi_{5} \neq 0$ alternatif hipotezi sınanır. Hesaplanan F istatistiği Pesaran vd. (1999: 20) çalışmasında hazırlanan kritik değerlerle karşılaştırtılacaktır. Eğer hesaplanan F istatistiği üst sınırın üzerinde ise, değişkenler arasında eş bütünleşme olmadığını söyleyen yokluk hipotezi red edilir. Eğer bir eş bütünleşme ilişkisinin varlığı bulunursa aşağıda yer alan eş bütünleşme modeli oluşturulacaktır:

$$
\begin{aligned}
R G_{t}=a+ & \gamma_{1} \sum_{i=1}^{k} R G_{t-i} \\
& +\gamma_{2} \sum_{i=0}^{k} T U F E_{t-i}+\gamma_{3} \sum_{i=0}^{k} D Y S Y_{t-i} \\
& +\gamma_{4} \sum_{i=0}^{k} S S O_{t-i}+\gamma_{5} \sum_{i=0}^{k} O Y N_{t-i}+\omega_{t}
\end{aligned}
$$

Schwarz bilgi kriteri kullanılarak belirlenecek olan gecikme uzunluklarının seçimi ARDL modelinde oldukça önemlidir. Ayrıca, her bir gecikme uzunluğu için hata terimlerinin seri korelasyon durumu da Breusch-Godfrey LM testi ile kontrol edilecektir. Son olarak, hata düzeltme gösterimi için dinamik kısa dönem katsayıları aşağıdaki denklem ile tahmin edilecektir: 


$$
\begin{array}{rl}
\Delta R G_{t}=a+\pi_{e c m} & E C M_{t-1}+\pi_{1} \sum_{i=1}^{k} \Delta R G_{t-i} \\
& +\pi_{2} \sum_{i=0}^{k} \Delta T U F E_{t-i}+\pi_{3} \sum_{i=0}^{k} \Delta D Y S Y_{t-i}+\pi_{4} \sum_{i=0}^{k} \Delta S S O_{t-i} \\
& +\pi_{5} \sum_{i=0}^{k} \Delta O Y N_{t-i} \\
& +e_{t}
\end{array}
$$

$E C M_{t-1}$; uzun dönem denge ilişkisine ait hata terimlerinin bir dönem gecikmeli değeridir (Denklem 6). $\pi_{\text {ecm }}$ ise uzun dönem dengesinin sağlanması için gereken düzelme hızını göstermektedir (Örneğin, uzun dönem dengesinde yaşanan bir sapmanın bir sapmanın aylık yüzde düzeltmesini gösterir).

$$
\begin{aligned}
E C M_{t}=R G_{t}-a- & \gamma_{1} \sum_{i=1}^{k} R G_{t-i} \\
& \quad-\gamma_{2} \sum_{i=0}^{k} T U F E_{t-i}-\gamma_{3} \sum_{i=0}^{k} D Y S Y_{t-i}-\gamma_{4} \sum_{i=0}^{k} S S O_{t-i}-\gamma_{5} \sum_{i=0}^{k} O Y N_{t-i}(6)
\end{aligned}
$$

\section{Bulgular}

Tablo 1'de çalışmada kullanılan değişkenlerin durağanlık özelliklerinin belirlenmesine yönelik Augmented Dickey Fuller (ADF) ve Philips-Perron (PP) birim kök testi sonuçları yer almaktadır. Bu testin sonuçlarına göre TÜFE ve DYSY düzeyde durağandır ve bütünleşme derecesi bu iki değişkenin I(0)'dır. ADF birim kök testinin sonuçlarına göre RG, SSO ve OYN değişkenleri ise düzeyde durağan değildir ve birinci farkları alındığında durağan hale gelmektedir. Yani bu üç değişkenin bütünleşme dereceleri I(1)'dir.

Tablo: 1

\section{Değişkenlerin Augmented Dickey Fuller(ADF) ve Philips-Perron(PP) Testi}

\begin{tabular}{|l|l|l|l|l|}
\hline Variable & ADF Test with intercept & \multicolumn{2}{l|}{ Philips-Perron with intercept } \\
\hline & Level & First Difference & Level & First Difference \\
\hline LnRG & -0.323 & $-6.352^{*}$ & -0.064 & $-6.347^{*}$ \\
\hline LnTUFE & $-5.3006^{*}$ & $-12.41^{*}$ & $-10.2005^{*}$ & $-22.961^{*}$ \\
\hline LnDYSY & $-4.7009^{*}$ & $-7.698^{*}$ & $-4.699^{*}$ & $-32.445^{*}$ \\
\hline LnSSO & -0.666 & $-2.621^{* *}$ & -1.183 & $-10.718^{*}$ \\
\hline LnOYN & -1.051 & $-9.556^{*}$ & -0.917 & $-9.594^{*}$ \\
\hline
\end{tabular}

-3.53 (\%1 Level) $-2.906(\% 5$ Level) -2.591 (\%10 Level)

$* 0.01, * * 0.005, * * * 0.1$ 
Birim kök testlerinin sonucunda değişkenlerden bazıları düzeyde durağan iken bazılarının düzeyde durağan olmamaları sınır testi yaklaşımının (ARDL modelinin) kullanılması için geçerli bir neden oluşturmaktadır.

Tablo 2'de, 3 numaralı denklemdeki gecikme uzunluklarının nasıl belirlendiği görülmektedir. Bunun için maksimum gecikme uzunluğu 8 olarak alınmış ve her gecikme için Schwarz Bilgi Kriteri (SIC) değerleri ve ardışık bağımlılık sorununun belirlenmesi amacıyla Breusch-Godfrey LM test değerleri hesaplanmıştır. Tabloda görüldüğü gibi en küçük SIC değeri 1 gecikme için söz konusudur. Ayrıca, bu gecikme uzunluğunda hata terimleri için seri korelasyon durumu söz konusu değildir. Bu nedenle sınır testinin bir gecikme ile yapılması uygun görülmüştür.

Tablo: 2

Sınır Testi İçin Gecikme Sayısının Belirlenmesi

\begin{tabular}{|c|c|c|}
\hline Lags & SIC & BG LM \\
\hline 8 & -4.38 & 0.116 \\
\hline 7 & -4.32 & 0.028 \\
\hline 6 & -4.45 & 0.166 \\
\hline 5 & -4.42 & 0.095 \\
\hline 4 & -4.45 & 0.051 \\
\hline 3 & -4.59 & 0.231 \\
\hline 2 & -4.51 & 0.192 \\
\hline $\boldsymbol{1}$ & $\mathbf{- 4 . 7 2}$ & $\mathbf{0 . 3 7 6}$ \\
\hline
\end{tabular}

Tablo 3 'te yer alan eş bütünleşme sınır testinin sonuçları yokluk hipotezinin $\% 5$ güven düzeyinde reddedilmesi gerektiğini göstermektedir. Tablo 3 'te 4.35 olarak hesaplanan $\mathrm{F}$ istatistiği $\% 90$ ve \%95 güven düzeyindeki kritik değerlerden büyük olduğu için RG, TÜFE, DYSY, SSO ve OYN arasında uzun dönemli bir ilişkinin var olduğu görülmektedir.

Tablo: 3

\section{Eş bütünleşme Analizleri için Sınır Testi}

\begin{tabular}{|c|c|c|c|c|}
\hline $\mathbf{k}$ & Sinır Testi (F) & \multicolumn{3}{|c|}{ Kritik Değerler } \\
\hline \multirow{3}{*}{4} & \multirow{3}{*}{4.35} & & Alt Sınır & Üst Sinır \\
\cline { 3 - 5 } & & $\% 90$ & 2.45 & 3.52 \\
\cline { 3 - 5 } & & $\% 95$ & 2.86 & 4.01 \\
\cline { 3 - 5 } & F Stat 5.82 & $\% 99$ & 3.74 & 5.06 \\
\hline \multirow{2}{*}{$\mathrm{R}^{2}=0.629$} & $(0.000)$ & $(0.211)$ & $8.66(0.891)$ & Ramsey RESET 1.606 \\
& & & & \\
\hline Jarque-Bera $\chi^{2}$ & & & & \\
$10.67(0.004)$ & & & & \\
\hline
\end{tabular}

Değişkenler arasındaki uzun dönemli ilişkinin belirlenmesi için oluşturulan ARDL (1,0,0,0,1) modeline ait katsayılar Tablo 4'te yer almaktadır. ARDL (1,0,0,0,1) modelinin tahmin sonuçları ve sonuçlara dayanılarak hesaplanan uzun dönem katsayı tahminleri TÜFE, DYSY ve SSO'nun RG üzerinde pozitif, OYN değişkeninin ise negatif 
etkisi olduğunu göstermektedir. Fakat TÜFE, SSO ve OYN değişkenleri istatistiksel olarak anlamlı bir etkiye sahipken DYSY'nın ekonomik büyüme (GSYİH) üzerinde anlamlı bir etkisinin olmadığı görülmektedir. Daha önce yapılan çalışmalarda da DYSY'nın ulusal sermayeyi dışlayıcı etkilerine bağlı olarak ekonomik büyüme üzerinde anlamlı bir etkisinin olmadığına dair benzer sonuçlara ulaşılmıştır (Carkovic \& Levine, 2002: 1; Aitken \& Harrison, 1999: 605).

Tablo: 4

ARDL (1,0,0,0,1) Sonuçları ve Hesaplanan Uzun Dönem Katsayıları

\begin{tabular}{|l|l|l|}
\hline Değișkenler & Katsayı & t İstatistiği \\
\hline Sabit & 3.2981 & $5.513^{*}$ \\
\hline RG(-1) & 0.7117 & $14.622^{*}$ \\
\hline TUFE & 0.0207 & $2.115^{* *}$ \\
\hline DYSY & 0.0033 & 0.762 \\
\hline SSO & 0.1017 & $5.002^{*}$ \\
\hline OYN & 0.0041 & 0.258 \\
\hline OYN(-1) & -0.0271 & $-1.729^{* * *}$ \\
\hline Uzun Dönem Katsayılar & \multicolumn{2}{|l|}{} \\
\hline TUFE & 0.0719 & $2.26^{* *}$ \\
\hline DYSY & 0.0117 & 0.792 \\
\hline SSO & 0.3531 & $8.21^{*}$ \\
\hline OYN & -0.0801 & $-1.96^{* * *}$ \\
\hline$R^{2}=0.992$ & F Stat 1302.88(0.000) & B-G LM 1.0702 $(0.58)$ \\
\hline White $\chi^{2} 29.47(0.288)$ & Ramsey RESET 7.16(0.009) & Jarque-Bera $\chi^{2} 4.28(0.117)$ \\
\hline
\end{tabular}

Parantez içerisindeki değerler olasllık değerlerini göstermektedir.

$* 0.01, * * 0.005$, ***0.1

Tablo: 5

ARDL (4,0,0,3,1) Modelinin Hata Düzeltme Modeli Sonuçları

\begin{tabular}{|l|l|l|}
\hline Değişkenler & Katsayı & T İstatistiği \\
\hline Sabit & 0.0086 & $1.821^{* * *}$ \\
\hline Ecm $(-1)$ & -0.5657 & $-2.12^{* *}$ \\
\hline$\Delta$ RG $(-1)$ & 0.1300 & 0.491 \\
\hline$\Delta$ RG $(-2)$ & -0.2077 & -1.602 \\
\hline$\Delta$ RG $(-3)$ & -0.4133 & $-3.571^{*}$ \\
\hline$\Delta$ RG $(-4)$ & -0.2077 & $-2.25^{* *}$ \\
\hline$\Delta$ TUFE & 0.0655 & 1.158 \\
\hline$\Delta$ DYSY & 0.0055 & $2.054^{*}$ \\
\hline$\Delta$ SSO & 0.1672 & $6.466^{*}$ \\
\hline$\Delta$ SSO $(-1)$ & 0.0878 & $2.618^{* *}$ \\
\hline$\Delta$ SSO $(-2)$ & 0.0710 & $2.133^{*} *$ \\
\hline$\Delta$ SSO $(-3)$ & 0.1185 & $3.84^{*}$ \\
\hline$\Delta$ OYN & 0.0061 & 0.451 \\
\hline$\Delta$ OYN $(-1)$ & 0.0034 & 0.239 \\
\hline $\mathrm{R}^{2}=0.646$ & F Stat 6.761(0.000) & B-G LM 3.041 $(0.314)$ \\
\hline White $\chi^{2} 12.26(0.548)$ & Ramsey RESET 1.761(0.08) & Jarque-Bera $\chi^{2} 3.041(0.3145)$ \\
\hline Parantez içerisindeki &
\end{tabular}

Parantez içerisindeki değerler olasılık değerlerini göstermektedir.

$* 0.01, * * 0.005$, ***0.1 
Hata düzeltme modeli, RG, TÜFE, DYSY, SSO ve OYN arasındaki kısa dönem ilişkileri ortaya çıkarmak için kullanılmıştır. Hata düzeltme katsayısının t istatistiği, değişkenler arasında kısa dönemli bir ilişkinin var olduğunu gösterecek biçimde istatistiksel olarak anlamlı ve negatif bir sonuç elde edildiğini göstermektedir. Hata düzeltme teriminin katsayısı uzun dönemde yaşanan bir şokun kısa dönemde uyarlama hızını göstermektedir. Buna göre, uzun dönem dengede yaşanan bir sapmanın \%56'sı her üç aylık dönemde düzelme göstermektedir.

Son olarak, parametre kararlığını test etmek amacıyla CUSUM durağanlık testi uygulanmıştır. Grafik 1'de görülen CUSUM testi sonuçlarına göre modelin hata terimlerinin kümülatif toplam değerleri \%5 kritik sınır aralığı içinde yer almaktadır. Buna ek olarak, parametrelerin sabitliğinin test edilmesi amacıyla Yinelemeli Katsayı Testi (Recursive Coefficient Test) uygulanmıştır. Bu testin sonuçları, denklemin tahmin edilmesi için daha fazla veri eklendiğinde, hesaplanan katsayı değerlerinde anlamlı bir değişim yaşanmadığını göstermektedir. Genel olarak, kararlılık testleri değişkenler arasındaki uzun dönemli ilişkinin kararlı değişkenler üzerine kurulu olduğunu göstermektedir.

Grafik: 1

Kısa Dönem ECM Modeli için Kararlılık Testleri

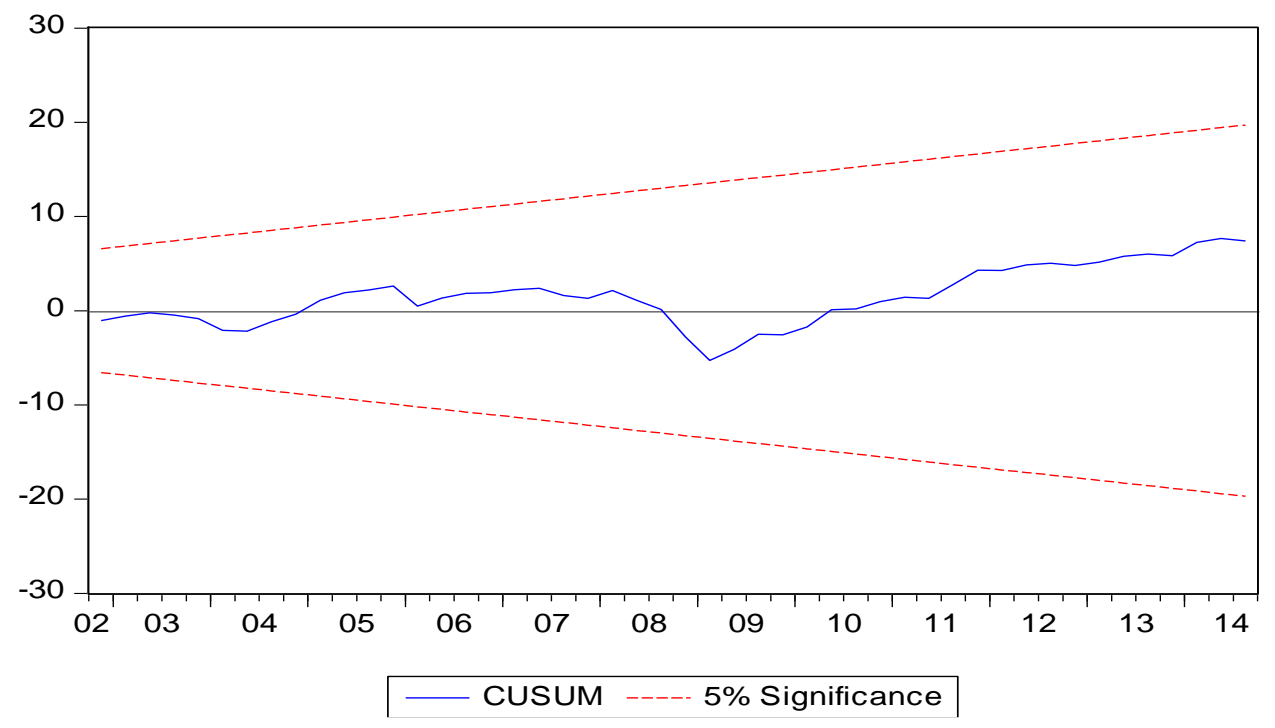



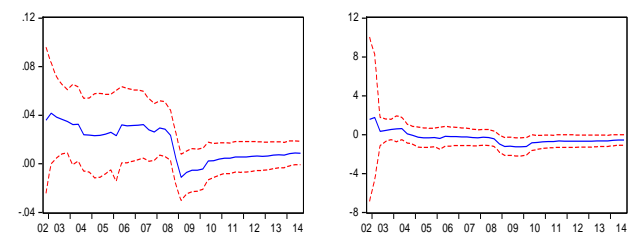

-Recursive C(1) Esimates

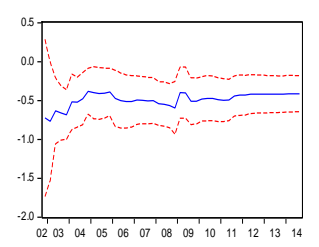

- Recursive C(5) Esimates
$-\rightarrow-2$ SSE

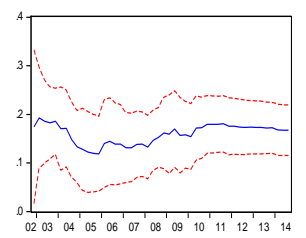

$-\begin{aligned} & - \text { Recursive C(9) Esimales } \\ & ---22 \text { SE. }\end{aligned}$

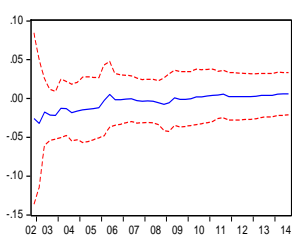

- Recursive C(13) Estinates
-- \pm 2 SEE

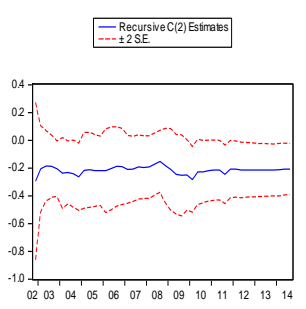

- Recursive C(6) Estinates
$--- \pm 2 \mathrm{SE}$

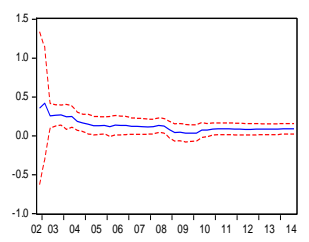

- Recursive C(10)Esimates
--- \pm 2 SE.

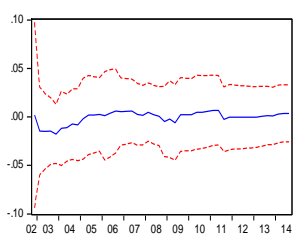

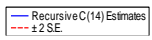
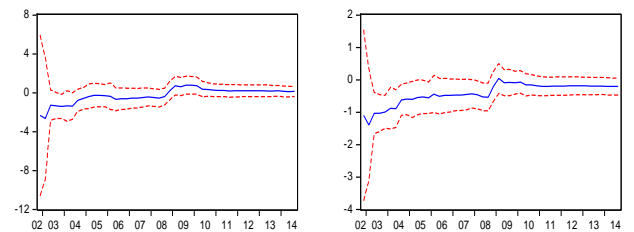

- Recursive C(3) Esinates

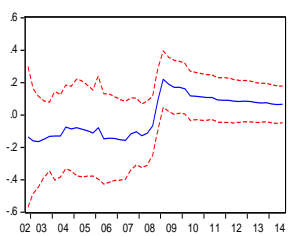

\begin{tabular}{l}
- Recursive C(7) Esimates \\
\hline -- \pm 2 S.E.
\end{tabular}

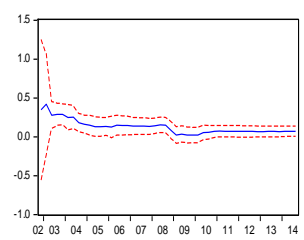

- RecursiveC(11) Estimates

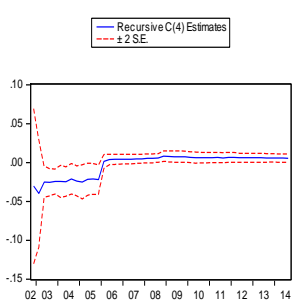

- Recursive C(8) Estimates
$-- \pm 2 S E$

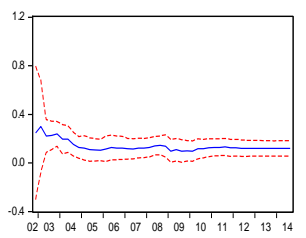

- Recursive C(12) Esimates

\section{Sonuç}

Bu çalışmada Türkiye'nin reel GSYİH'sı üzerinde TÜFE, SSO, DYSY ve OYN'un etkileri 1998:Ç1 den 2014:Ç3'e kadar üçer aylık veriler kullanılarak araştırılmıştır. $\mathrm{Bu}$ çalışmanın ilgili literatürdeki diğer çalışmalardan farklı yönü, nominal döviz kurları yerine reel döviz kurlarındaki oynaklık değerlerinin kullanılmasıdır. Değişkenler arasında uzun dönemli eş bütünleşme ilişkisinin varlığı, ARDL Sınır testi kullanılarak incelenmiştir. Elde edilen sonuçlara göre; Türkiye'de TÜFE, DYSY ve SSO, reel GSYİH üzerinde pozitif bir etkiye sahipken, reel döviz kuru oynaklığının negatif bir etkiye sahip olduğu görülmektedir. Uzun dönemde enflasyon ve yatırımlar ekonomik büyüme üzerinde pozitif ve anlamlı bir etkiye sahiptir. Makul oranda bir enflasyon oranı, ekonomik büyümeye katkıda bulunmaktadır. Bununla birlikte, doğrudan yabancı sermaye yatırımları uzun dönemde büyüme üzerinde anlamlı bir etkiye sahip değildir. Reel döviz kuru oynaklığı ise uzun dönemde bir dönem gecikmeli olarak büyüme üzerinde negatif ve anlamlı bir etkiye 
sahiptir. Modelimiz farklı varyans, seri korelasyon ve dışlanmış değişken sorunlarından bağımsızdır. Ayrıca, CUSUM değerleri kritik sınırlar içerisinde dağılmaktadır. Bu sonuçlara göre, modelimizin yapısal olarak kararlı olduğu görülmektedir.

Gelişmekte olan bir ekonomide, büyüme hedeflerinin gerçekleşmesi için daha fazla miktarda hammadde ve ara mal ithalatı ihtiyacı ortaya çıkacaktır. Buna karşın, teknoloji düzeyi, pazar gücünün zayıf olması gibi çok sayıda nedene bağlı olarak ihracat potansiyeli de nispeten daha düşük olacaktır. Dış ticaret dengesinde bu duruma bağlı olarak, yabancı para talebindeki artış ülkenin para biriminde dalgalanmalara ve yüksek oynaklığa yol açabilmektedir. 2001 yılında kur politikasının değişmesi ve 2008 yılında yaşanan finansal krizin etkisiyle, Türk Lira (TL)'sının yabancı para birimleri karşısındaki değerinde yaşanan değişimlerin makroekonomik istikrar üzerindeki etkileri giderek daha fazla hissedilmeye başlamıştır. Bu noktada, döviz kuru oynaklığının ekonomik istikrar üzerindeki olumsuz etkilerini azaltmak amacıyla Türkiye Cumhuriyet Merkez Bankası (TCMB)'nın piyasalardaki etkinliği giderek artmaktadır. TCMB, Kasım 2011'den itibaren fiyat istikrarını ve finansal istikrarı temel alarak döviz kurunda aşırı oynaklığı azaltmak amacına yönelik politikalar uygulamaya başlamıştır. Bu dönemde, aşırı kur oynaklığını azaltmaya yönelik bir politika aracı olarak Rezerv Opsiyonu Mekanizması (ROM) uygulamaya başlanmış ve faiz koridorunun üst sınırı aktif olarak kullanılarak ek parasal sıkılaştırma gerçekleştirilmiştir. Bu politika araçları ile sermaye akımlarına karşı TL üzerindeki olası aşırı değerlenme veya değer kaybetme baskısının azaltılması hedeflenmiştir (Değerli \& Fendoğlu, 2013: 1). Halihazırda, ROM TCMB tarafından sermaye akımlarındaki oynaklıklar nedeniyle ortaya çıkan döviz kuru oynaklığının azaltılmasında etkin bir politika aracı olarak kullanılmaktadır (Ermişoğlu vd., 2013: 1-6). Dolayısıyla, ROM gibi döviz kuru oynaklığının azaltılmasında etkin politika araçlarına sahip olan TCMB'nin sahip olduğu konum, döviz kuru oynaklığının ekonomik istikrar üzerindeki olumsuz etkilerinin yumuşaması açısından kritik öneme sahiptir.

\section{Kaynaklar}

Aitken, B.J. \& A.E. Harrison (1999), "Do Domestic Firms Benefit From Direct Foreign Investment? Evidence from Venezuela", American Economic Review, 82: 605-618.

Aghion, P. \& P. Bacchetta \& R. Ranciere \& K. Rogoff (2009), "Exchange Rate Volatility and Productivity Growth: The Role of Financial Development", Journal of Monetary Economics, 56: 494-513.

Ahmad, A. \& N. Ahmad \& S. Ali (2013), "Exchange Rate and Economic Growth in Pakistan (19752011), MPRA Paper No. 49395: 740-746.

Ahmad, N. \& M. Luqman (2012), “A Dynamic Analysis of the Relationship among Inflation, Investment, Population Growth, Export and Economic Growth in Pakistan", Asian Journal of Research in Business Economics and Management, 2(8): 175-182.

Ahmad, N. \& M.F. Hayat \& M. Luqman \& S. Ullah (2012a), "The Casual Links between Foreign Direct Investment and Economic Growth in Pakistan", European Journal of Business and Economics, 6: 20-21. 
Ahmad, N. \& M. Luqman \& M.F. Hayat (2012b), "The Importance of Investment for Economic Growth: Evidence from Pakistan", Interdisciplinary Journal of Contemporary Research in Business, 4(4): 680-684.

Ahmad, N. \& U.T.S. Joyia (2012), "The Relationship between Inflation and Economic Growth in Pakistan: An Econometric Approach", Asian Journal of Research in Business Economics and Management, 2(9): 38-48.

Aizenman, J. (1992), "Exchange Rate Flexibility, Volatility and the Patterns of Domestic and Foreign Investment", IMF Staff Papers, 890-922.

Akay, H.K. \& M. Nargeleçekenler (2006), "Finansal Piyasa Volatilitesi ve Ekonomi”, Ankara Üniversitesi SBF Dergisi, 61(4): 5-32.

Azid, T. \& M. Jamil \& A. Kousar (2005), "Impact of Exchange Rate Volatility on Growth and Economic Performance: A Case Study of Pakistan, 1973-2003”, The Pakistan Development Review, 44(4): 749-775.

Barro, R.J. (1995), "Inflation and Economic Growth", National Bureau of Economic Research (NBER) Working Paper No. 5326:1-38.

Bollerslev, T. (1986), “Generalized Autoregressive Conditional Heteroskedasticity”, Journal of Econometrics, 31: 307-327.

Bruno, M. \& W. Easterly (1998), "Inflation Crises and Long-Run Growth", Journal of Monetary Economics, 41: 3-26.

Campa, J. \& L.S. Goldberg (1993), "Investment in Manufacturing, Exchange Rates and External Exposure”, NBER Working Paper, No.4378.

Campa, J. \& L.S. Goldberg (1995), "Investment in Manufacturing, Exchange Rates and External Exposure", Journal of International Economics, 38(3-4): 297-320.

Carkovic, M. \& R. Levine (2002), “Does Foreign Direct Investment Accelerate Economic Growth?”, Social Science Research Network, 1-23.

Carkovic, M. \& R. Levine (2005), "Does Foreign Direct Investment Accelerate Economic Growth?" in: Does Foreign Direct Investment Promote Development?, eds. Theodore H. Moran \& Edward D. Graham \& Magnus Blomström, Washington, DC: Institute for International Economics : 195-220.

Chen, J. (2012), "Real Exchange Rate and Economic Growth: Evidence from Chinese Provicial Data (1992-2008), Paris School of Economics Working Paper No: 2012-05: 1-27.

Cheung, Y.W. \& K.S. Lai (1998), "Economic Growth and Stationarity of Real Exchange Rates: Evidence from Some Fast-Growing Asian Countries", Pasific Basin Finance Journal, 6: 61-76.

Değerli, A. \& S. Fendoğlu (2013), "Döviz Kuru Beklentileri ve TCMB Para Politikası”, S. 2013-02, TCMB Ekonomi Notlart.

Dornbush, R. (2001), "Fewer Monies Better Monies”, NBER Working Paper, No.8324:1-12.

Eichengreen, B. (2007), "The Exchange Rate and Economic Growth", Commission on Growth and Development Working Paper No. 4.

Ermişoğlu, E. \& A. Oduncu \& Y. Akçelik (2013), "Rezerv Opsiyonu Mekanizması ve Kur Oynaklığı”, S. 2013-04, TCMB Ekonomi Notları.

Ghosh, A. \& S. Phillips (1998), “Warning: Inflation May Be Harmful”, International Monetary Fund, 45(4): 662-710. 
Güloğlu, B. \& A. Akman (2007), “Türkiye'de Döviz Kuru Oynaklığının SWARCH Yöntemi İle Analizi”, Finans Politik \& Ekonomik Yorumlar, 44(512): 43-51.

He, Q. (2010), "Expanding Varieties in the Nontraded Goods Sector and the Real Exchange Rate Depreciation", Journal of International and Global Economic Studies, 3(2): 19-38.

Huybens, E. \& B.D. Smith (1999), "Inflation, Financial Markets and Long Run Real Activity”, Journal of Monetary Economics, 43(2): 283-315.

Javed, H.Z. \& M. Farooq (2009), "Economic Growth and Exchange Volatility in Case of Pakistan", Pakistan Journal of Life and Social Sciences, 7(2): 112-118.

Khaliq, A. \& I. Noy (2007), "Foreign Direct Investment and Economic Growth: Empirical Evidence from Sectoral Data in Indonesia", Indonesia Journal and Review, 01-27.

Kogid, M. \& R. Asid \& J. Lily \& D. Mulok \&N. Loganathan (2012), “The Effect of Exchange Rate on Economic Growth: Empirical Testing on Nominal Versus Real", IUP Journal of Financial Economics, 10(1): 7-17.

Miles, W. (2006), “To Float or Not To Float? Currency Regimes and Growth”, Journal of Economic Development, 31 (2): 91-105.

Mahmood, I. \& E. Major (2011), "Macroeconomic Variables and FDI in Pakistan", European Journal of Scientific Research, 55(3): 388-393.

Mubarik, Y.A. (2005), "Inflation and Growth: An Estimate of the Threshold Level of Inflation in Pakistan", SBP Research Bulletin, 1(1): 35-44.

Mughal, F.A. \& N. Aslam \& M.A. Jabbar \& W. Ullah (2012), "Inflation, Inflation Uncertainty and Output Growth, Are They Related? A Study on South East Asian Economies 19602010", Journal of Basic and Applied Scientific Research, 2(6): 6108-6114.

Musyoki, D. \& G. Pokharial \& M. Pundo (2012), "The Impact of Real Exchange Rate Volatility on Economic Growth: Kenyan Evidence”, Business and Economic Horizons, 7(1): 59-75.

Naseer, S. \& F. Abbasi \& M.M. Far (2012), “Any Relations between Nominal Interest Rate and Inflation Rate Upon Fisher Effect”, Journal of Basic and Applied Scientific Research, 2(4), 4000-4007.

Quartey, P. (2010), "Price Stability and the Growth Maximizing Rate of Inflation for Ghana", Scientific Research Journal, 1(3): 180-194.

Pesaran, M.H. \& Y. Shin (1999), “An Autoregressive Distributed Lag Modelling Approach to Cointegration Analysis", Econometrics and Economic Theory in The 20th Century: The Ragnar Frisch Centennial Symposium, Chapter 11, Cambridge University Press.

Pesaran, M.H. \&Y. Shin \& R.J. Smith (2001), "Bound Testing Approaches to the Analysis of Long Run Relationships", Journal of Applied Econometrics, 16(3): 289-326.

Rodrik, D. (2008), “The Exchange Rate and Economic Growth", Brookings Papers on Economic Activity, 2: 365-412.

Shahzad, H. \& S. Malik (2011), "Inflation and Economic Growth: Evidence from Pakistan", International Journal of Economics and Finance, 3(5): 262-276.

Vieira, F.V. \& M. Holland \& C. Gomes de Silva \& L.C. Bottecchia (2013), "Growth and Exchange Rate Volatility: A Panel Data Analysis", Applied Economics, 45(26): 3733-3741.

Tarawalie, A.B. (2010), "Real Exchange Rate Behaviour and Economic Growth: Evidence from Sierra Leone", South African Journal of Economic Management Sciences, 13(1): 8-23. 